\title{
A metodologia de Ilhas de Racionalidade Interdisciplinar na promoção da Alfabetização Científica e Tecnológica: Um dinamismo indispensável
}

The methodology of islands of Interdisciplinary Rationality in the promotion of Scientific and Technological Literacy: An indispensable dynamism

La metodología de Islas de Racionalidad Interdisciplinar en la promoción de la Alfabetización Científica y Tecnológica: Un dinamismo indispensable

\section{Resumo}

O presente artigo é um estudo de teses e dissertações que abordam a metodologia de Ilhas de Racionalidade Interdisciplinares (IRI) na formação de professores de ciências. No levantamento realizado encontramos seis trabalhos, que foram analisados via pressupostos da Análise Textual Discursiva (ATD). Como compreensões emergentes sinalizamos: 1) A necessidade de trabalhos que abordam a metodologia de IRI com vistas a promover uma Alfabetização Científica e Tecnológica (ACT); 2) A abordagem da ACT em um viés humanista e transformador, possibilitando uma tomada de decisão consciente aos sujeitos sobre questões de caráter social; e 3) A formação de professores como intelectuais transformadores, visto a demanda em uma formação que contribua para a promoção da ACT.

Palavras-chave: Ilhas de racionalidade interdisciplinar; Alfabetização científica e tecnológica; Intelectuais transformadores.

\begin{abstract}
This article is a study of the theses and dissertations that approach the methodology of Islands of Interdisciplinary Rationality (IIR) in the training of science teachers. In the survey, we found six studies that were analyzed using Textual Discursive Analysis (DTA) assumptions. As emerging understandings, we signal: 1) The need for works that address the IRI methodology to promote Scientific and Technological Literacy (STL); 2) The approach of STL in a humanistic and transformative bias, aiming to enable conscious decision making to subjects on issues of a social character; and 3) the formation of teachers as transformative intellectuals, given the demand of training that contributes to the promotion of STL.
\end{abstract}

Keywords: Islands of interdisciplinary rationality; Scientific and technological literacy; Transformative intellectuals.

\section{Resumen}

Este artículo es un estudio de tesis y disertaciones que abordan la metodología Islas Interdisciplinarias de Racionalidad (IRI) en la formación de profesores de ciencias. En la encuesta se encontraron seis trabajos, los cuales fueron analizados utilizando los supuestos del Análisis Textual Discursivo (ATD). Como entendimientos emergentes, señalamos: 1) La necesidad de trabajos que aborden la metodología IRI con miras a promover la Alfabetización Científica y tecnológica (ACT); 2) El enfoque de ACT con una perspectiva humanista y transformadora, que permita a los sujetos tomar una decisión consciente sobre temas sociales; y 3) La formación de docentes como intelectuales transformadores, dada la demanda de formación que contribuya a la promoción de ACT.

Palabras clave: Islas de racionalidad interdisciplinaria; Alfabetización científica y tecnológica; Intelectuales transformadores. 


\section{Introdução}

Muitos professores concordam com resultados de estudos que sinalizam a necessidade de um ensino de forma contextualizada, que tenha relações com o cotidiano dos estudantes, as aulas, principalmente nas disciplinas da área de ciências, continuam sendo realizadas de forma fragmentada e descontextualizada (Bettanin, 2003). Entretanto, o que se vê hoje, é uma prática pedagógica de quadro negro completamente desconexa da aplicação do conhecimento de ciência para a vida.

Apesar de mais de uma década cientes dessa necessidade, a contextualização continua problemática e o foco permanece na preparação dos estudantes para a realização do vestibular, um ensino que se baseia na memorização de informações e aplicação de fórmulas de maneira mecânica. Chassot (2003), por exemplo, já sinalizava a urgência em mudar a prática docente, indicando que os professores deveriam ter coragem para promover esta mudança e buscar alternativas para fomentar uma alfabetização cientifica aos sujeitos a fim de torná-los mais críticos.

Concordamos com o autor que esta não é uma tarefa fácil, e que a educação deve promover nos estudantes a capacidade de relacionar o conhecimento científico com as situações cotidianas vivenciadas. Além de fomentar a habilidade de pensar em diversas alternativas para enfrentar as adversidades que emergem do seu contexto, desenvolvem competências presentes no eixo cultural e social e são condições para que os indivíduos exerçam um papel consciente da cidadania.

Neste sentido, Fourez (1997) apresenta um método denominado Ilhas de Racionalidade Interdisciplinar (IRI)1, a fim de propiciar uma Alfabetização Científica e Tecnológica (ACT), o qual apresenta oito etapas que visam possibilitar aos estudantes essa construção por meio da abordagem de um problema concreto. A proposta de Fourez surge da necessidade em possibilitar aos educandos uma educação que possa ser estendida para a vida, pois considera que o ensino de ciências deve demonstrar que a ciência possibilita novas formas de enxergar o mundo e de agir sobre ele. Por este motivo deve ser relevante para os estudantes e possibilitar uma tomada de decisão consciente em assuntos cotidianos.

Nossas maneiras de ensinar as ciências estão centradas em teorias e modelos interessantes para os alunos? nossos cursos de ciências não são às vezes uma maneira de fazê-los entrar no mundo dos cientistas mais do que uma forma de ajudá-los a explorar seu próprio mundo? (Fourez, 1994, p. 63, tradução nossa).

Desta forma, considerando a problemática do ensino de ciência e confiantes na potencialidade da ACT, o presente artigo tem como objetivo geral, compreender como se efetiva a ACT nos trabalhos que abordam a metodologia de IRI na formação de professores de ciências. Buscando entender: “Quais as contribuições da metodologia de IRI para a promoção da ACT na e para a formação de professores de ciências? O ponto de vista a partir do qual analisamos os trabalhos, está balizado na perspectiva de ACT de Gérard Fourez, respaldados no viés humanista freireano e na concepção crítica de ACT de Henry Giroux.

\section{Alfabetização Científica e Tecnológica}

A ACT, surgiu no final do século XIX, como uma metáfora para a alfabetização. Naquele período, saber ler e escrever tornou-se fundamental, e todos encontravam uma certa vantagem, os patrões viam a possibilidade de obter mão de obra qualificada, e os empregados, vislumbravam certa emancipação. (Fourez, 1994).

\footnotetext{
${ }^{1}$ Neste artigo utilizamos o termo Ilhas de Racionalidade Interdisciplinar (IRI), pois o autor cita alguns tipos de Ilhas de Racionalidade e a interdisciplinar é uma delas. Ressaltamos, entretanto, que alguns autores indicam Ilhas Interdisciplinares de Racionalidade (IIR) como a representação interdisciplinar construída pelo emprego das etapas indicadas por Fourez.
} 
O ensino iniciou um processo de democratização e foi desta forma que a escola se tornou obrigatória, e que por muito tempo questionou-se qual o efeito desta "democratização" na educação. Sobre este ponto, o autor indaga: "Os trabalhadores aprenderam a ler e escrever simplesmente para se tornarem bons consumidores, leitores de anúncios ou das instruções de seus empregadores? Ou, o conhecimento lhes deu acesso a uma emancipação social e cultural? (...)” (Fourez, 1994, p. 17, tradução nossa).

Esses questionamentos propiciam importantes reflexões acerca da ACT. Durante muito tempo apenas saber ler e escrever era o indicativo para um sujeito ser considerado alfabetizado. No entanto, o objetivo da ACT vai muito além, pois é concebida como uma forma de propiciar com que os conhecimentos científicos e tecnológicos possibilitem certa autonomia aos sujeitos (Auler \& Delizoicov, 2001; Chassot, 2003; Ruas, 2017). Uma pessoa alfabetizada é capaz de analisar de forma crítica as construções científicas e tecnológicas, e tomar decisões conscientes frente a esses assuntos. Nesse sentido,

(...) uma alfabetização científica e técnica dever passar por um ensino de ciências em seu contexto e não como uma verdade que será um puro fim nela mesma. Alfabetizar técnico-cientificamente não significa que se dará cursos de ciências humanas no lugar de processo científicos. Significará sobretudo que se tomará consciência de que as teorias e modelos científicos não serão bem compreendidos se não se sabe o porquê, em vista de que, e para que foram inventados (Fourez, 1994, p.81, tradução nossa, grifos do autor).

Essa tomada de consciência de teorias e modelos científicos propiciada pela ACT permite aos sujeitos abandonar a postura de receptor passivo para adquirir certa autonomia no universo em que está inserido. Neste viés, concordamos com o sentido metafórico anteriormente mencionado argumentando que:

(...) a alfabetização é mais que o simples domínio psicológico e mecânico de técnicas de escrever e de ler. É o domínio destas técnicas em termos conscientes. (...) Implica numa autoformação de que possa resultar uma postura interferente do homem sobre seu contexto. (Freire, 1980, p.111).

Para que a alfabetização seja compreendida em seu viés amplo, como o defendido por Freire (1980), Auler e Delizoicov (2001), sinalizam que a ACT pode ser concebida em duas perspectivas, a reducionista e a ampliada. Na perspectiva reducionista ignora-se a existência de mitos que contribuem para uma leitura ingênua da realidade. Nesta perspectiva a ciência é considerada sacrossanta, na qual o conhecimento é apresentado como infalível sem oportunidades de debates e reflexões. Segundo os autores, na perspectiva reducionista se espera que os conteúdos "operem por si mesmos", na perspectiva ampliada, eles são considerados pontes para a compreensão de temas sociais, ou seja, oportunizam uma leitura da realidade em que os sujeitos estão inseridos.

Neste trabalho, defendemos a perspectiva ampliada da ACT, pois nela considera-se um analfabeto científico o sujeito incapaz de realizar uma leitura do universo no qual está inserido (Fourez, 1994; Chassot, 2003). Assim, um sujeito seria:

(...) alfabetizado científica e tecnologicamente quando seus saberes promoverem uma certa autonomia (possibilidade de negociar suas decisões frente às pressões naturais ou sociais), uma certa capacidade de comunicar (encontrar as maneiras de dizer), e um certo domínio e responsabilidade, frente a situações concretas. (Fourez, 1994, p. 62, tradução nossa, grifos do autor).

A explicitação do autor sinaliza a importância da perspectiva ampliada para ACT como promotora de autonomia que favoreça a comunicação de decisões que indiquem domínio de conhecimento e ação responsável frente a situações concretas.

Nesse sentido, considera-se importante que o professor, ao objetivar a ACT, tenha a consciência destas duas perspectivas a fim de definir seu objetivo e compreender quais passos deverão ser dados para atingi-lo. Caso contrário, corre-se o risco de perpetuar uma postura fatalista e uma percepção ingênua da realidade, fatores que vão contra a essência da ACT defendida por Fourez (1994). Ele apresenta nove critérios que considera importantes para a promoção da ACT, e que devem ser considerados pelos professores, ao se questionarem sobre o que é necessário para estar científico-tecnicamente 
alfabetizado, e como propiciar a ACT. Os critérios são: 1) o bom uso dos especialistas; 2) o bom uso das caixas-pretas; 3) o bom uso de modelos simples; 4) o uso e a invenção de modelos disciplinares; 5) o bom uso das metáforas ou comparações; 6) o bom uso das traduções; 7) o bom uso da negociação; 8) O bom uso da articulação entre saberes e decisões e 9) o bom uso dos debates técnicos, éticos e políticos².

Com base na nossa compreensão dos critérios apresentados por Fourez (1994) inferimos que ao objetivar a ACT não se deve resumir os estudantes a um ensino onde só há a recepção mecânica de informações, mas deve-se priorizar a participação ativa de cada sujeito e do coletivo que compõe o contexto escolar. Assim, compreendemos que é a partir de situações concretas e ações interdisciplinares que o caráter ativo e coletivo do processo de construção de conhecimentos na escola se edifica. Neste viés, Fourez (1994) propõe uma metodologia ${ }^{3}$ para construção de Ilhas Interdisciplinares de Racionalidade (IRI), modelo utilizado para representar situações concretas, e possibilitar uma ACT aos sujeitos.

\subsection{A metodologia de Ilhas de Racionalidade Interdisciplinar de Gérard Fourez}

O conhecimento científico disseminado nas escolas, está pautado no viés disciplinar transposto com o objetivo de atender os objetivos do ensino, o que se configura em pouca, ou nenhuma manifestação de interesse pelos estudantes, pois geralmente o que lhes é transmitido não apresenta nenhuma relação com a vida cotidiana. (Fourez, 1994; Santos \& Mortimer, 2002; Bettanin, 2003).

Fourez (1994; 2003) questiona a eficácia do ensino disciplinar, em propiciar aos estudantes uma compreensão sobre as questões científicas e tecnológicas, visando sua aplicação em situações concretas da vida social, pessoal ou política. Para o autor, são poucos os problemas concretos que podem ser resolvidos e abordados de forma adequada pelos conhecimentos de uma única disciplina escolar. $\mathrm{O}$ autor cita como exemplo o problema de isolar uma casa termicamente, indicando que para ser abordado com os estudantes, o professor necessita de conhecimentos da física, engenharia, direito, de noções de economia, de ética, estética e ecologia.

Desta forma, quando se é necessário resolver uma determinada circunstância, como o problema do isolamento térmico citado anteriormente, o autor sugere a criação de um modelo ou representação interdisciplinar para a situação. Para a construção desses modelos denominados de IRI, são necessários, além dos conhecimentos disciplinares, conhecimentos de situações relacionadas à vida cotidiana, para que se possa compreender as situações e tomar decisões conscientes sobre elas.

A IRI “visa produzir uma representação teórica apropriada em uma situação precisa e em função de um projeto determinado" (Fourez, 1994, p. 121), permitindo ao sujeito comunicar-se e tomar decisões conscientes sobre o assunto, considerando os conhecimentos científicos e tecnológicos. Isso não significa descobrir uma nova teoria, mas sim, criar uma teorização adequada para a situação problema.

A construção da IRI inicia-se com a proposição de uma situação problema que orientará o desenvolvimento do projeto, e que geralmente é apresentada aos estudantes como uma pergunta. Como por exemplo:

“(...) O cinto de segurança deve ser obrigatório? Pode-se, em certas condições, introduzir um objeto de metal em um forno de microondas? Que precauções se deve tomar quando se usa soda cáustica, ácido clorídrico ou outros produtos para desentupir encanamentos? (...)" (Fourez, 1994, p.133).

\footnotetext{
${ }^{2}$ Para maiores informações vide o capitulo três da obra Alfabetización científica y tecnológica: acerca de las finalidades de la enseñanza de las ciencias (Fourez, 1994).

3 Maingain, Dufour \& Fourez (2008) usam o termo método para a construção de uma IRI. No entanto, compreendemos que os procedimentos apresentados pelos autores, se aproximam de uma metodologia, visto que os passos apresentados para a construção de uma IRI não precisam ser seguidos rigorosamente.
} 
Nesse sentido, a situação problema tem por objetivo mobilizar conhecimentos para despertar o desejo de construir significados ao ensino alicerçado nas disciplinas escolares que participarão do projeto que será desenvolvido. Logo, compreendemos que devam ser abordados temas do cotidiano dos alunos. Dessa forma, entendemos que a metodologia de IRI sob a abordagem de uma situação problema, visa desarticular a ênfase dada ao ensino puramente vinculado na disciplina escolar, objetivando abordar aspectos relacionados ao cotidiano dos estudantes, respaldados em conhecimentos científicos.

Para atingir os objetivos mencionados, Fourez (1994) apresenta uma metodologia para a construção da IRI, sinalizando algumas etapas que servem para delimitar o trabalho, alcançando assim, sua finalidade. Estas etapas são caminhos metodológicos com vistas a elaborar uma representação interdisciplinar de uma situação, integrando a contribuição de diversas disciplinas (Maingain, Dufour \& Fourez, 2008). Para a construção da IRI, não é necessário seguir à risca as etapas propostas, pode-se modificar a ordem e incluir etapas a fim de adaptá-las de acordo com as especificidades do contexto e de cada situação problema abordada.

Fourez (1994) explica as etapas de construção de uma representação interdisciplinar a partir de um exemplo de situação problema vinculada a um projeto técnico para uma ferramenta: um ferro de passar roupa. O projeto seria desenvolvido por acadêmicos de um curso de formação inicial de professores, os quais seriam os construtores da Ilha de racionalidade, indicada como um folheto explicativo para orientar vendedores de ferro de passar roupas. Nesse folheto os acadêmicos apresentariam informações técnicas e conceituais relacionadas com o ferro de passar roupas e seu processo de funcionamento. As etapas de construção da IRI iniciam por:

1- Fazer um clichê da situação estudada: esta etapa pode ser comparada como uma problematização inicial. Para Fourez trata-se de um conjunto de representações (corretas ou erradas) que a equipe de investigação, professores e estudantes, tem sobre a situação problema. Para isso a equipe será interrogada em um brainstorming. Bettanin (2003), abordando a problemática: "Como realizar a instalação elétrica em uma residência?" traz alguns exemplos de questionamentos que podem ser realizados nesta etapa:

Por que se usa fio de cobre e não outros metais nas instalações elétricas? Como se consegue obter energia elétrica? Desde quando o homem usa energia elétrica em sua residência? Quais os efeitos do choque no organismo humano? Como proceder quando alguém leva um choque? Podemos usar fio da mesma espessura para a instalação de um chuveiro e de uma lâmpada? Como funciona uma usina hidrelétrica? A usina hidrelétrica provoca algum tipo de poluição ao meio ambiente? (Bettanin, 2003, p. 39).

2- $\quad$ Panorama espontâneo: etapa composta por seis ações (a. lista dos autores envolvidos; b. pesquisa de normas e condições impostas pela técnica; c. lista dos jogos de interesses e das tensões; d. listagem das caixas-pretas; e. lista de bifurcações e f. lista de especialistas e especialidades pertinentes). $\mathrm{O}$ autor define como caixa-preta aspectos técnicos, materiais ou conceituais, relacionados com a situação problema, passíveis de ser investigados pelos construtores da IRI. Considerando o ferro de passar roupas seriam possíveis caixas-pretas sobre a explicação do processo de aquecimento por efeito joule, a escolha da temperatura para cada tipo de tecido, formato da base do ferro, o material do qual é construído etc. Especificamente sobre o panorama espontâneo, Fourez (1994, p. 112) sinaliza que "trata-se de ampliar o contexto do clichê. Utiliza-se uma grade de leitura que permita realizar questões desprezadas durante a primeira etapa".

3- Consulta aos especialistas e às especialidades: Esta etapa é um pouco mais longa que as vistas anteriormente, corresponde ao momento de abertura das caixas-pretas, as questões para as quais a equipe não possui respostas e precisam consultar uma fonte segura de informação. Nesse caso, o especialista pode ser um pesquisador ou um artigo produzido por ele ou alguém que faz uso do conhecimento de forma técnica e que com a experiência, adquiriu especialidade. Assim, da listagem realizada na etapa anterior são selecionados alguns especialistas a ser consultados, considerando sempre, a situação problema, o projeto e a representação que se pretende construir com aqueles estudantes. 
4- Ida à prática: Nesta etapa ocorre um confronto entre a própria experiência e a situação concreta, deixa-se de pensar teoricamente na situação problema para enxergá-la na prática. Esta etapa pode ser abordada de várias maneiras: leitura de um artigo científico, entrevista com uma pessoa com reconhecida especialidade sobre o assunto, desmontagem de um equipamento, visita a uma indústria, dentre outras.

\section{5- $\quad$ Abertura aprofundada de algumas caixas-pretas e descoberta de princípios disciplinares que formam}

a base de uma tecnologia: esta etapa caracteriza-se como um aprofundamento de determinado assunto discutido no projeto, presente na caixa-preta que foi aberta, é facultativa a busca por especialistas neste momento. A abertura das caixas deve estar relacionada ao contexto, aos produtores (professores e estudantes) e aos destinatários da IRI (geralmente estudantes e comunidade escolar). Neste momento, busca-se atingir alguns objetivos da ACT, como a autonomia dos sujeitos frente à questões científico-tecnológicas. Bettanin (2003) explicita que questões de natureza cultural também constituem caixas-pretas passíveis de abertura.

6- Esquematização global da tecnologia ou da representação interdisciplinar: esta etapa consiste na elaboração de uma síntese da IRI, pode ser uma figura, um esquema ou um resumo que se possa construir uma representação teórica da situação.

7- Abertura das caixas-pretas sem a ajuda de especialistas: todo indivíduo se depara ao longo da vida com situações adversas, que exige dele uma tomada de decisão consciente acerca de situações concretas. Como nem sempre há especialistas disponíveis, deve-se incentivar os estudantes a construírem representações interdisciplinares a fim de propiciar certa autonomia, possibilitando um posicionamento ativo para tomar atitudes sobre situações cotidianas. Construir seu esquema sem consultar um modelo ou indicar possibilidade para ampliar ou aprofundar a representação esquematizada.

8- Síntese da IRI produzida: nesta última etapa organiza-se de forma escrita ou oral a IRI desenvolvida durante o projeto. Fourez explicita que a síntese produzida deve abranger algumas questões:

Em que medida o que nós estudamos nos ajuda a negociar com o mundo tecnológico enfocado? O que ganhamos em termos de uma certa autonomia dentro de um mundo científico-tecnológico e na sociedade em geral? De que forma os saberes obtidos nos ajudam a discutir com maior precisão as decisões a tomar? (Fourez, 1994, p.121).

A metodologia de IRI pode ser abordada nos diferentes níveis de ensino básico ou superior, e apresenta um ponto positivo que a diferencia das demais propostas com viés interdisciplinar, que são as etapas de execução. No entanto, cabe sinalizar que segundo o autor elas não se configuram como uma "receita" pronta e acabada. Compreende-se que a discussão em equipe para seleção de caixas, a negociação no processo de abertura direciona o projeto e as etapas e dessa forma não pode ser considerado como prescritivo. Os questionamentos explicitados pelo autor, configuram-se como sugestões, devendo ser considerados na execução da metodologia, o contexto em que será aplicado e as especificidades dos sujeitos envolvidos. Desta forma, deve-se analisar se as etapas sugeridas pelo autor podem ser seguidas na ordem, ou, se devem ser realizadas adaptações, modificações ou inserções, a fim de atender as necessidades da situação em estudo.

Fourez (1994) propõe a metodologia de IRI a fim de propiciar uma ACT, objetivando aos sujeitos um posicionamento crítico e autônomo com capacidade de dialogar com seus pares e tomar decisões conscientes acerca de questões do seu cotidiano.

\section{Metodologia}

Foi realizada a busca por teses e dissertações disponíveis na base de dados da Biblioteca Virtual de Teses e Dissertações (BDTD) no período de 2009-2020. A palavra-chave utilizada para o levantamento dos estudos foi Ilhas de Racionalidade Interdisciplinar ou Ilhas Interdisciplinares de Racionalidade. 
Pela pesquisa, encontramos um quantitativo de vinte trabalhos que abordam a área de Ilhas de Racionalidade Interdisciplinar. A partir da leitura dos títulos, palavras-chave e resumos foram excluídos catorze trabalhos, pois não apresentavam discussões referentes à formação de professores de ciências, que é a linha de interesse.

Dentre os seis trabalhos que abordam a metodologia de Ilhas de Racionalidade Interdisciplinar na formação de professores de ciências, encontra-se uma pesquisa que envolve a formação de assessores pedagógicos (Strefezza, 2020). Consideramos a análise deste trabalho, que abrange várias áreas de conhecimento, além do ensino de ciências, pois abordamos um viés interdisciplinar neste estudo. Além disso, compreendemos relevante realizar a análise de um trabalho que teve como sujeitos de pesquisa autores que possuem como parte de sua função prover formações continuadas aos professores.

Assim, os trabalhos que utilizamos como objeto de estudo nesta pesquisa, seguem explicitados no Quadro 1:

Quadro 1: Trabalhos analisados que abordam a metodologias de IRI na formação de professores de ciências.

\begin{tabular}{|c|l|c|c|}
\hline \multicolumn{2}{|c|}{ Título } & Tipo & Autoria \\
\hline T1 & Inserção da interdisciplinaridade na formação de licenciandos em física. & Tese & Lisboa (2017) \\
\hline T2 & $\begin{array}{l}\text { Interdisciplinaridade, problematização e contextualização: a perspectiva de um } \\
\text { grupo de professores em um curso de formação. }\end{array}$ & Tese & Ruas (2017) \\
\hline T3 & $\begin{array}{l}\text { A interdisciplinaridade em diferentes contextos educacionais: contribuições para o } \\
\text { ensino de biologia }\end{array}$ & Tese & $\begin{array}{c}\text { Nicoletti } \\
(2017)\end{array}$ \\
\hline T4 & $\begin{array}{l}\text { Construção de ilha de racionalidade baseada na temática formigas: uma experiência } \\
\text { para professores de ciências em formação inicial. }\end{array}$ & Dissertação & Costa (2019) \\
\hline T5 & $\begin{array}{l}\text { Alfabetização científica e tecnológica na formação inicial de professores de } \\
\text { química. }\end{array}$ & Dissertação & $\begin{array}{c}\text { Oliveira } \\
(2019)\end{array}$ \\
\hline T6 & $\begin{array}{l}\text { As ilhas interdisciplinares de racionalidade na formação continuada de assessores } \\
\text { pedagógicos: uma proposta interdisciplinar para o ensino de temas socioambientais }\end{array}$ & Dissertação & $\begin{array}{c}\text { Strefezza } \\
(2020)\end{array}$ \\
\hline
\end{tabular}

Fonte: Autoras.

Os seis trabalhos identificados foram analisados via Análise Textual Discursiva (ATD), a qual constitui uma metodologia de análise de dados, que nos últimos anos vem sendo cada vez mais utilizada em pesquisas qualitativas da área de ensino. Ela baseia-se em um processo emergente de construção de compreensões, que são validadas em formas de produções escritas (Moraes \& Galiazzi, 2013).

Os movimentos de análise baseiam-se na unitarização, categorização e escrita de metatextos. Desta forma, na primeira etapa da análise, realizamos a leitura na íntegra dos seis trabalhos, que constituem o "corpus" de análise, a fim de iniciar o processo de desconstrução e unitarização. O objetivo desta etapa é conseguir notar os sentidos do texto em sua essência, buscando elementos que possam trazer informações acerca da questão de pesquisa em estudo. A partir dos movimentos de análise emergiram 283 unidades de significado (trechos que apresentavam significações, ou, respondiam à questão de pesquisa), em seguida atribuiu-se um título a cada unidade. Cabe destacar, que a partir desta etapa já existem tessituras interpretativas por parte do pesquisador.

Dando sequência ao processo de análise, os títulos das unidades foram agrupados em unidades semelhantes, constituindo as sete categorias iniciais. A partir de um novo movimento de reagrupamento de categorias que se assemelham, atingiu-se cinco categorias intermediárias, e em uma nova ação de aproximação de categorias, emergiram as três categorias finais, que compõem os metatextos. 
A terceira etapa do movimento de análise que constitui a ATD, se caracteriza pela escrita do metatexto. Nele são explicitadas as compreensões emergentes do processo de análise por meio de uma articulação envolvendo as unidades de significado, organizadas no processo de categorização, bem como compreensões teóricas e os entendimentos construídos pelo pesquisador ao longo do processo de análise. Neste artigo, apresentaremos o metatexto de análise intitulado: "A metodologia de IRI na formação de professores de ciências: a necessária abordagem da ACT", que se constitui pelas unidades de significado e categorias emergentes do processo de análise; respaldados em teóricos e nas compreensões desveladas. Os movimentos de análise formam uma rede de novos entendimentos no qual o metatexto se aflora; podendo ser vislumbrado no próximo tópico.

\section{Resultados e Discussão}

No metatexto apresentado a seguir, ressaltamos o ponto de vista de que o desenvolvimento de uma estratégia de ensino diferenciado requer do professor a compreensão adequada do processo e de sua função como mediador do processo de construção de conhecimentos, por parte dos estudantes. Esses conhecimentos são necessários para o exercício da docência no contexto do século XXI e parece urgente uma formação que contribua para a consolidação daqueles já integrados na sua estrutura cognitiva e servem de base para a efetivação da profissionalidade do futuro docente. Profissionalidade que contribua para a emancipação social e cultural dos estudantes, de forma a desenvolver sua criticidade, possibilitando participar ativamente na construção e transformação da sua sociedade.

\subsection{A metodologia de IRI na formação de professores de ciências: a necessária abordagem da ACT}

O contexto do século XXI sinaliza a urgência em incluir na proposta educativa questões que promovam a ACT, neste sentido a abordagem Ciência-Tecnologia-Sociedade e a proposta de IRI apresentada por Fourez (1994) buscam atingir a ACT, incluindo a compreensão de que a Ciência enquanto criação humana, está presente na vida de todos os cidadãos. Por isso deve ser considerada parte essencial nos currículos escolares a inclusão de uma abordagem científica e tecnológica, para que os sujeitos compreendam que as construções provindas destes eixos não são neutras, portanto, devem ser analisados sob uma lente crítica (Acevedo, Vázquez \& Manassero, 2003). Os avanços da ciência e tecnologia tem se instaurado na sociedade, tornando a tomada de consciência um fator imprescindível, por isso se faz necessário, um ensino de ciências sob um viés problematizador da realidade, onde a aprendizagem apresente significações para os estudantes (Fagundes et al, 2009).

Neste sentido, Giroux (1990) explicita que a alfabetização como uma ideologia deve ser encarada como um construto social, implícita a visão de mundo do sujeito, além disso deve estar alicerçada a um projeto ético e político visando dignificar e ampliar as possibilidades de vida e autonomia humanas. O autor sinaliza que a ACT deveria tornar-se uma pré-condição para a emancipação social e cultural, enraizado em um espírito de crítica em um projeto que possibilite aos indivíduos participar ativamente na transformação da sua sociedade.

O fragmento T5U9 ${ }^{4}$ sinaliza alguns dos objetivos da ACT:

T5U9: (...) verificamos a importância de termos o conhecimento científico como um dos conhecimentos que sustenta nossas reflexões que fundamentarão nossas ações na sociedade em que estamos inseridos. Trabalhar para que o conhecimento científico seja acessível, no sentido de promover às pessoas uma nova forma de ver o mundo e os

\footnotetext{
${ }^{4}$ Uma das etapas da metodologia da ATD é a codificação, pois é importante que o pesquisador proceda suas análises de modo que saiba a todo o momento quais documentos deram origem àquelas unidades. Para isso, utilizamos códigos que indicam a origem de cada unidade. Logo, o código T5U9, representa o trabalho cinco (T5) e unidade de significado de número nove (U9).
} 
acontecimentos que nele acontece, e poder agir sobre ele de maneira embasada, consciente e crítica cientificamente é um dos objetivos que vem sendo almejados pela ACT no Ensino de Ciências (Costa, 2019, p. 27)

O trecho sinaliza a importância do conhecimento científico ao destacar que é "como um dos conhecimentos que sustenta nossas reflexões que fundamentarão nossas ações na sociedade em que estamos inseridos” (Costa, 2019, p,27). No entanto, cabe ressaltar que não é apenas o conhecimento científico disciplinar que propicia aos sujeitos uma nova forma de ver o mundo. Os sujeitos adquirem uma análise da sua realidade por meio de uma integração de conhecimentos, dentre eles os científicos, mas não se deve excluir aqueles adquiridos na vida cotidiana. Por este motivo, alguns autores (Fourez, 1994; Ferreira, Muenchen \& Auler, 2019; Klein, Pereira \& Muenchen, 2021) sinalizam a importância da abordagem de um problema concreto para promover a ACT. Neste viés, o trecho T3U13 citando Fourez (1994) traz uma complementação das ideias apresentadas no trecho anterior:

T3U13: Fourez aborda que a união dos saberes prévios aos cientificamente aceitos favorece a Alfabetização Científica e Tecnológica (ACT), uma vez que "permitem uma certa autonomia (possibilidade de negociar suas decisões frente às pressões naturais ou sociais), uma certa capacidade de comunicação (encontrar as maneiras de dizer), e um certo domínio e responsabilidade, frente a situações concretas (Nicoletti, 2017, p. 151, grifo nosso).

Como sinalizado no trecho acima, a ACT permite certa autonomia, capacidade de comunicação e responsabilidade frente a situações concretas. Acreditamos que ela vai além, pois possibilita com que os sujeitos se encontrem no mundo, e mais que isso, que descubram qual papel desempenham na sociedade e identifiquem a potencialidade da sua voz, nas decisões de questões cotidianas que os envolvem diretamente.

Para Gramsci, a alfabetização tornou-se um referencial e uma modalidade de crítica para o desenvolvimento de formas de educação contra-hegemônicas em torno do projeto político de criar uma sociedade de intelectuais (no sentido mais amplo do termo) que pudesse captar a importância de desenvolver esferas públicas democráticas como parte da luta da vida moderna no combate à dominação, bem como tomar parte ativa na luta pela criação das condições necessárias para tornar as pessoas letradas, para dar-lhes uma voz tanto para dar forma à própria sociedade, quanto para governá-la (Giroux, 1990, p. 2-3).

Corroboramos com o autor, ao sinalizar que a alfabetização não pode ser concebida apenas como uma habilidade técnica de ler palavras, mas sim, como um fundamento para uma ação cultural para a liberdade. Neste viés, os indivíduos afirmam seu direito não apenas de ler, mas de compreender e transformar suas experiências pessoais, buscando uma sociedade mais justa e igualitária. Giroux (1990, p. 5) sinaliza que neste sentido a alfabetização é fundamental para que a sociedade reconheça a potencialidade da sua voz como parte de um projeto mais amplo com vistas ao empoderamento dos indivíduos. O autor sinaliza que professores e alunos, dentro de determinadas formações sociais, são o ponto de partida para analisar a forma como se constroem ativamente suas experiências pessoais dentro das relações de poder. Tais formações, contribuem para a compreensão sobre como a construção social dessas experiências lhes proporcionam a oportunidade de dar sentido e força a suas necessidades e vozes, como meio de um empoderamento individual e social. Neste viés, Giroux (1990) sinaliza o que é alfabetização para Freire:

(...) alfabetização para Freire é parte do processo pelo qual alguém se torna autocrítico a respeito da natureza historicamente construída de sua própria experiência. Ser capaz de nomear a própria experiência é parte do que significa "ler" o mundo e começar a compreender a natureza política dos limites bem como das possibilidades que caracterizam sociedades mais amplas (Giroux, 1990, p. 5).

Para Freire, a alfabetização tem o objetivo maior do que ler meras palavras, ela propicia a leitura do mundo. Neste sentido, a linguagem e o poder mantêm uma íntima relação, na busca pela construção e legitimação das práticas sociais. Giroux

\footnotetext{
${ }^{5}$ Como o presente artigo aborda a análise de teses e dissertações, e as unidades de significado são constituídas por trechos destes trabalhos, consideramos necessária a identificação dos autores.
} 
(1990) citando Gramsci sinaliza que a linguagem possui uma característica tanto hegemônica, quanto contra hegemônica, pois serve como ferramenta, tanto para silenciar as vozes dos oprimidos, quanto para legitimar relações sociais opressivas. Para Freire, a linguagem e o poder estão inextricavelmente entrelaçados e proporcionam uma dimensão fundamental da ação humana e da transformação social. Ao universalizar determinadas ideologias, procurava subordinar o mundo da ação e da luta humanas aos interesses dos grupos dominantes (Giroux, 1990, p. 5). No entanto, é importante destacar que a linguagem também pode ser encarada como um terreno sobre o qual lutas, sonhos e aspirações se edificam, ganhando significado em um discurso de crítica e de possibilidade.

Em um sentido mais amplo e politizado, compreendemos que a alfabetização apresenta uma gama de possibilidades e competências que possibilitam as diversas relações e experiências entre os educandos e o universo (Giroux, 1990). A alfabetização desenvolve nos sujeitos as condições práticas e teóricas para se tornarem agentes ativos na luta para expandir suas possibilidades de emancipação. Porém, a emancipação neste cenário tem um sentido mais limitado, mas continua sendo uma condição prévia de extrema importância para o engajamento em lutas de relações de poder, permitindo com que os oprimidos retirem o manto de alienação que vedam seus olhos, e a mordaça que veta a potencialidade de sua voz.

Dessa maneira, compreendemos que para que a ACT abranja uma ação como parte narrativa da libertação, os professores devem se atentar a sua prática pedagógica evitando o viés reducionista, colocando os educandos como agentes ativos nos processos de ensino e de aprendizagem. Nesse sentido, o fragmento T2U15, traz algumas considerações:

T2U15: A ACT é uma importante estratégia educacional para combater a pedagogia bancária, criticada por Freire, pois esta oferece ao oprimido um ensino sem dialogicidade e sem problematizar a realidade (Ruas, 2017, p. 30).

Como forma de reforçar seu argumento, a autora traz uma explicitação de Freire (1987), o qual sinaliza a importância de inserir os educandos no mundo, a fim de propiciar o reconhecimento das problemáticas que emergem do universo em que estão inseridos.

Quanto mais se problematizam os educandos como seres no mundo e com o mundo, tanto mais se sentirão desafiados. Tão mais desafiados, quanto mais obrigada responder ao desafio. Desafiados, compreendem o desafio na própria ação de captá-lo. Mas, precisamente porque captam o desafio como um problema em suas conexões com outros, num plano de totalidade, e não como algo petrificado, a compreensão resultante tende a tornar-se crescentemente crítica, por isso, cada vez mais desalienada (Freire, 1987, p.70).

Concordamos com as explicitações do autor e sinalizamos que a alfabetização estabelece relações de conhecimento não apenas o que os professores ensinam, mas também aqueles que os estudantes trazem para as salas de aula, como parte das suas identidades pessoais e sociais, fruto da produção de conhecimento do grupo social no qual estão inseridos. O trecho T2U15 apresenta a crítica à pedagogia bancária de educação, a alfabetização no viés freireano, é tida como uma leitura de mundo e da palavra,

(...) é lançar as bases teóricas para uma análise mais completa de como se produz o conhecimento e de como se constroem as subjetividades no interior de relações de interação, nas quais professores e alunos procuram fazer-se presentes como autores ativos de seus próprios mundos (Giroux, 1990, p, 12-13).

Neste sentido, a alfabetização visa proporcionar a autonomia dos indivíduos, para que se posicionem ativamente em questões de cunho social, analisando de forma crítica e consciente os construtos científicos e tecnológicos.

Fourez (1994), apresenta algumas habilidades que considera necessária para classificar um indivíduo como alfabetizado cientificamente. O autor cita os critérios propostos peça Associação de Professores de Ciências dos Estados Unidos (NSTA).

Uma pessoa alfabetizada científica e tecnologicamente é capaz de: 


\section{Utilizar os conceitos científicos e integrar valores e saberes para tomar decisões responsáveis no dia a dia.}

Este conceito está relacionado a capacidade de tomada de decisão consciente e responsável frente a questões que envolvem ciência e tecnologia. Segundo o autor esta proposição considera inaceitável o ensino de ciências que não apresente vínculo com a realidade dos alunos "Não é possível continuar por muito tempo impondo programas escolares sobrecarregados, com conteúdos ora incoerentes ora irrelevantes em relação às necessidades atuais (Fourez, 1994, p. 19, tradução nossa).

Compreender que a sociedade exerce controle sobre as ciências e as tecnologias, bem como as ciências e as tecnologias refletem a sociedade.

A falta de compreensão desta proposição pode incorrer no erro de compreender as ciências e as tecnologias como neutras e sacrossantas. Os sujeitos muitas vezes compreendem que as ciências e as tecnologias produzem impactos na sociedade, mas a recíproca também ocorre a ciência e a tecnologia deve ser concebida como um reflexo das necessidades sociais. Neste viés, um sujeito alfabetizado é capaz de compreender esta relação, e principalmente, reconhece quando estas relações não estão caminhando no sentido do bem-estar social, mas, marcadas pelas intencionalidades das relações de poder.

Compreender que a sociedade exerce controle sobre as ciências e as tecnologias por meio do viés das subvenções que a elas concede

Fourez sinaliza como uma habilidade do indivíduo alfabetizado cientificamente reconhecer que é direito da sociedade exercer influência sobre o uso dos conhecimentos científicos e tecnológicos, visto que é a sociedade quem fomenta as atividades dos cientistas.

Reconhecer tanto os limites como a utilidade das ciências e das tecnologias para o progresso do bem-estar humano.

Nesta proposição, Fourez (1994) explicita a necessidade de que a ciência seja reconhecida pelos benefícios que podem trazer à sociedade. No entanto, o autor sinaliza que "no plano social, a ciência e a tecnologia podem ser tanto fator de opressão quanto de emancipação". Considerando esse cenário o autor sinaliza a urgência de desenvolver o espírito crítico nos alunos, para que sejam capazes de julgar conscientemente os benefícios e malefícios provindos das inovações científicas e tecnológicas, notando quanto estas possuem um objetivo voltado para o bem-estar da sociedade, ou para potencializar as relações de poder.

O fragmento T5U7 apresenta algumas explicitações acerca das questões apresentadas nas proposições:

T5U7: (...) o objetivo da ACT norteia uma forma de empoderar os cidadãos com o conhecimento científico, tornando-os capazes de compreender questões que envolvam esse conhecimento, podendo ser cidadãos ativos perante situações que ocorrem na sociedade. Temos a compreensão de que a finalidade da ACT deve ser capacitar os cidadãos para que possam utilizar o conhecimento científico, entre os demais conhecimentos que possui, como fonte de reflexão e compressão dos acontecimentos que ocorrem na sociedade, posicionando e agindo diante deles (Costa, 2019, p. 21, grifo nosso).

A ACT possibilita com que os indivíduos se tornem empoderados, com a capacidade de utilizar os conhecimentos a fim de relacioná-los com questões que envolvam assuntos sociais, posicionando-se crítica e conscientemente sobre elas. No entanto, para que estas questões se efetivem é necessário que as proposições defendidas por Fourez (1994), apresentadas até o momento e as que serão apresentadas, sejam contempladas.

\section{Conhecer os principais conceitos, hipóteses e teorias científicas e é capaz de aplicá-los}

Fourez (1994, p. 28) sinaliza que esta proposição pode trazer vários questionamentos, como, "quais os principais conceitos e teorias científicas? como aplicá-los?”, dentre outros. Esta proposição visa suprir demandas em dois sentidos: um cultural e outro prático. O primeiro proporciona aos indivíduos, conhecimentos que os levem a notar quais as implicações de determinada teoria, o segundo deve possibilitar os sujeitos a falar sobre um conhecimento científico. 


\section{Apreciar as ciências e as tecnologias pela estimulação intelectual que elas suscitam.}

Esta proposição apresenta tanto o caráter cultural quanto o prático apresentado anteriormente. Fourez comenta que reflete um prazer intelectual em posicionar-se perante um desafio.

Compreender que a produção dos saberes científicos depende, ao mesmo tempo, de processos de pesquisas e de conceitos teóricos.

A ACT vai além de questões sobre conhecimento, ou da aplicação de resultados científicos e tecnológicos. Busca promover uma tomada de consciência sobre as questões científica e tecnológicas e sua relação com os fenômenos da sociedade e da história, ou seja, busca abordar o caráter humanista e social do fazer científico. De acordo com Fourez (1994), " $a$ proposição sugere, então, que não serão alfabetizados aqueles e aquelas que não tiveram consciência das estruturas sociais necessárias ao desenvolvimento das tecnociências” (Fourez, 1994, p.31, tradução nossa).

\section{Saber reconhecer a diferença entre os resultados científicos e a opinião pessoal.}

Esta proposição visa evitar a compreensão de que as visões pessoais são subjetivas, e que os construtos que a ciência apresenta, sempre serão verdades totalmente objetivas. Neste sentido torna-se necessário sinalizar que as proposições científicas não são estáveis ou imutáveis, pois são advindas de uma comunidade específica marcada por ideologias, regras e valores.

Reconhecer a origem da ciência e compreender que o saber científico é provisório, e sujeito a mudanças a depender do acúmulo de resultados.

Neste item, Fourez (1994) sinaliza a necessidade de compreender que a ciência não deve ser considerada um dogma, visto que está sujeita a alterações dependendo das interações humanas, históricas e sociais.

\section{Compreender as aplicações das tecnologias e as decisões implicadas na sua utilização}

Fourez (1994) comenta que esta proposição pode ser compreendida de duas formas, uma mais ampla, outra mais restrita. A mais restrita estaria relacionada a simples compreensão instrumental, ou seja, seria o entendimento sobre o funcionamento de um aparelho, como o computador, por exemplo. Sobre a segunda colocação, o autor sinaliza que tem por objetivo possibilitar que os indivíduos não sejam apenas consumidores passivos, trata-se de uma perspectiva mais ampla:

\footnotetext{
"Se esta perspectiva mais ampla for escolhida a Alfabetização Científica e Tecnológica é mais do que a aprendizagem de receitas ou mesmo de comportamentos intelectuais face a ciência e a tecnologia: ela implica uma visão crítica e humanista da forma como as tecnologias (e mesmo as tecnologias intelectuais, que são as ciências) moldam nossa maneira de pensar, de nos organizar e de agir." (Fourez,1994, p.33, tradução nossa).
}

\section{Possuir saber e experiência suficientes para apreciar o valor da pesquisa e do desenvolvimento tecnológico.}

Fourez (1994) sinaliza que esta proposta traz consigo uma ambiguidade, pois remete a um objetivo cultural e humanista: o cultural se refere ao conhecimento que se tem sobre as ciências como uma forma de apreciá-las. O outro viés, voltado a uma leitura crítica, refere-se a importância de que os indivíduos tenham conhecimentos suficientes para se posicionar politicamente perante as questões sociais que envolvam a ciência e a tecnologia. Como sinalizado no fragmento T5U1, citando Fourez (2003):

T5U1: A Alfabetização Científica e Tecnológica (ACT) busca oferecer à população através do ensino do conhecimento científico e tecnológico, uma formação que possibilite a tomada de decisões em assuntos que relacionam o conhecimento científico e suas tecnologias, tendo compreensão e realizando questionamentos, possibilitando aos cidadãos serem pessoas ativas nos processos que envolvam esse tipo de conhecimento (Costa, 2019, p. 14, grifo nosso). 


\section{Extrair da formação científica uma visão de mundo mais rica e interessante.}

Sobre esta proposição Fourez sinaliza que "Para que as ciências enriqueçam a visão de mundo, é necessário que sejam estudadas e relacionadas aos projetos humanos que contribuíram para sua elaboração" (Fourez, 1994, p.27, tradução nossa).

Conhecer as fontes válidas de informação científica e tecnológica e recorra a elas quando diante de situações de tomada de decisões.

Esta proposição relaciona-se com três objetivos: o primeiro se refere ao conhecimento sobre fontes de informações úteis quando surge um problema; a segunda está relaciona a um saber prático, trata-se de um saber que não resulta de si mesmo, implica exercícios práticos, que envolvem desde o saber selecionar informações úteis, até saber descartá-las. A terceira, envolve a necessidade de criar o hábito de realizar investigações a fim de colocar em prática os dois objetivos citados.

E, por fim, o autor considera importante:

\section{Ter uma certa compreensão da maneira como as ciências e as tecnologias foram produzidas ao longo da história.}

Este critério busca reforçar algumas questões sinalizadas nas proposições anteriores, qual seja, a necessidade de compreender as dimensões sociais, culturais e econômicas que envolvem o desenvolvimento da ciência e tecnologia. Segundo Fourez, “(...) devemos duvidar de que seja alfabetizado cientifica e tecnologicamente aquela pessoa que não seja consciente da página da história da humanidade escrita por meio da produção das ciências e das tecnologias" (Fourez, 1994, p.36, tradução nossa).

As compreensões tecidas até o momento sugerem a notoriedade de fomentar a ACT nos estudantes a fim de formar cidadãos críticos e conscientes. Neste sentido, cabe realizar o seguinte questionamento: "Há a promoção da ACT nos trabalhos analisados?" Sobre esta questão é importante sinalizar que apenas dois trabalhos explicitaram se a metodologia de IRI, fomentou a ACT nos sujeitos de pesquisa. Como pode ser notado nos fragmentos T6U18 e T5U38:

T6U18: (...) pode-se concluir que a observação sistematizada, em todas as etapas, possibilitou constatar que a metodologia das IIR desenvolve nos indivíduos os atributos da ACT, se o processo for orientado pelo professor. Desta forma, este trabalho contribuiu para o desenvolvimento de um ensino menos fragmentado, desenvolvendo os atributos da ACT no processo de aprendizagem. (Strefezza, 2020, p. 114).

T5U38: Diante dessas considerações podemos considerar que participar de uma IIR pode ter favorecido uma formação na perspectiva da ACT. Mais estudos nesse sentido são necessários para investigar essa hipótese (Costa, 2019, p.103).

O trecho T5U38 sinaliza que a proposta desenvolvida possibilitou o desenvolvimento da ACT, mas que seria necessário mais estudo para a investigação da hipótese. É importante sinalizar que uma pesquisa de mestrado e doutorado possui um tempo limitado, logo é difícil sinalizar que os sujeitos de pesquisa se tornaram alfabetizados científica e tecnologicamente, visto que são ações que se efetivam na vivência com o mundo e com as adversidades que dele emergem. O que se pode sinalizar é se houveram indícios da promoção de uma alfabetização científica, o que é extremamente importante, pois os estudantes podem assumir uma identidade transformadora a partir destas ações. Desta forma, considera-se urgente que uma educação pautada na ACT se efetive nos currículos prescritos da Educação Básica, para que haja uma formação com significado, não apenas para preparar alunos para uma prova de vestibular. O que se deseja a partir de um ensino pautado na ACT é a formação de cidadãos que tenham a capacidade de tomar decisões conscientes, em questões de cunho social.

Mas como possibilitar tal formação? A partir das construções realizadas até o momento torna-se possível discutir o trecho T5U40: 
T5U40: “Quais aspectos devem ser contemplados na formação de professores de Química capazes de promover a ACT? (...) Ao nosso ver, o principal aspecto que deve ser contemplado na formação de professores de Química para que sejam capazes de promover a ACT é uma formação reflexiva (Costa, 2019, p. 105, grifo da autora).

Os aspectos que devem ser contemplados na formação de professores, que visam promover a ACT, são os apresentados por Fourez (1994), pautados pelo desejo de superação e transformação, a fim de reascender a potencialidades das vozes dos sujeitos na luta cotidiana. Para isso, é essencial somar a esse aspecto, a urgência em redefinir a natureza do trabalho docente, como intelectuais transformadores, como defendido por Freitas \& Queirós (2019, 2020a, 2020b). O modelo formativo dos professores como intelectuais, neste caso, é importante para a análise crítica tanto dos materiais que estruturam as relações pedagógicas que os professores estão envolvidos, quanto de suas práticas ideológicas.

Por isso compreendemos que a formação reflexiva apresentada no trecho T5U40, apresenta limitações, quando o objetivo é fomentar a ACT. Acreditamos que a formação de professores como intelectuais transformadores apresenta a mesma essência, de emancipação e transformação social, marcados nos objetivos da ACT.

A ACT, neste viés, possibilita compreender que a relação sociedade x ciência-tecnologia e ciência-tecnologia x sociedade, não são neutras, uma exerce influência sobre a outra. As construções científicas e tecnológicas devem estar voltadas para as necessidades da sociedade. A compreensão destas questões e das proposições apresentadas por Fourez (1994), propicia a formação de cidadãos alfabetizados no sentido mais amplo da palavra, de forma que ele terá a capacidade de analisar as construções científicas e tecnológicas, a fim de sinalizar possíveis relações de poder que possam emergir. Isso contribuirá principalmente, para que ele tenha uma visão ampla sobre a importância da ciência e tecnologia, não se limitando às informações incoerentes disponibilizadas em qualquer meio de informação, evitando assim, ter uma visão reducionista e negacionista acerca da ciência e tecnologia.

\section{Considerações Finais}

Buscamos a partir desse estudo contribuir para com a necessária reflexão sobre o processo formativo de professores para construção e desenvolvimento de práticas que promovam a alfabetização científica. Embora este trabalho tenha uma característica teórica, acreditamos que para promover um ensino a partir dos pressupostos da ACT, é necessária uma reflexão sobre a formação docente. Desta forma, acreditamos que se possa atingir os objetivos da ACT, bem como conscientizar os estudantes acerca do valor da ciência e sobre o ambiente científico-tecnológico que nos rodeia.

A partir deste estudo foi possível compreendermos como se desvela a ACT nos trabalhos que abordam a metodologia de IRI na formação de professores de ciências. Além disso, pudemos sinalizar a urgência de pesquisas nesse viés, visto que dos seis trabalhos analisados apenas dois discutem de forma explícita, quais as contribuições das propostas para a promoção da ACT.

Além disso, pela característica fenomenológica da ATD foi possível compreender como se apresenta a ACT nesses trabalhos. Por conseguinte, sinalizamos a urgência em pesquisas que explicitem os objetivos da ACT contemplados pela metodologia de IRI, visto que um dos eixos centrais da metodologia é fomentar a ACT aos sujeitos. Ademais, foi possível entender que a ACT possui um viés humanista e transformador, pois objetiva possibilitar aos sujeitos o reconhecimento da importância do seu papel na sociedade, bem como da potencialidade de sua voz em questões de caráter social. Desta forma, compreendemos que o modelo formativo de professores como intelectuais transformadores apresenta a mesma essência transformadora que a ACT.

Neste viés, cabe sinalizar que a abordagem da alfabetização contemplada neste trabalho visa o empoderamento não só dos alunos, mas também do professor como parte de um projeto mais amplo de reconhecimento e reconstrução de seu papel 
social e político. Assim, como Giroux (1990) sinaliza, nesses parâmetros a ACT é uma precondição para o engajamento no trabalho pedagógico e na ação social.

As compreensões tecidas neste estudo nos sinalizam para a necessidade em realizar pesquisas que fomentem a ACT a partir da metodologia de IRI. Além disso, compreendemos que para concretizar estas ações em salas de aula, em todos os níveis do ensino, é necessário realizar uma reflexão sobre a formação docente, pois compreendemos que esta prática não se concretiza de um dia para o outro. Acreditamos que para possibilitar a formação de um sujeito alfabetizado cientifica e tecnologicamente é necessário que a formação docente esteja pautada em um viés que se aproxime da essência da ACT, ou seja, deve estar pautada em um viés crítico, emancipatório e transformador. É por este motivo que sinalizamos a necessidade da formação de professores como intelectuais transformadores, por entendermos que este modelo formativo compactua dos mesmos ideais de transformação e formação crítica que a ACT. Logo, vislumbramos em trabalhos futuros podermos contribuir com pesquisas que articulem a metodologia de IRI objetivando fomentar uma ACT e a formação de professores como intelectuais transformadores, de modo a perpetuar um ensino transformador e igualitário.

\section{Referências}

Acevedo, J. A., Vázquez, A. M. A. \& Manassero (2003). (2003). Papel de la educación CTS en una alfabetización científica y tecnológica para todas las personas. Revista Electrónica de Enseñanza de las Ciencias, 2 (2), 80-111. http://reec.uvigo.es/volumenes/volumen2/REEC_2_2_1.pdf

Auler, D., \& Delizoicov, D. (2001). Alfabetização científico-tecnológica para quê? Ensaio Pesquisa em Educação em Ciências (Belo Horizonte), 3(2), 122134. https://www.scielo.br/pdf/epec/v3n2/1983-2117-epec-3-02-00122.pdf

Bettanin, E. (2003). As ilhas de racionalidade na promoção dos objetivos da alfabetização científica e técnica. Dissertação. Universidade Federal de Santa Catarina, Florianópolis, Brasil. https://repositorio.ufsc.br/handle/ 123456789/85223

Chassot, A. (2003). Alfabetização científica: uma possibilidade para a inclusão social. Revista brasileira de educação, (22), 89-100. https://www.scielo.br/j/rbedu/a/gZX6NW4YCy6fCWFQdWJ3KJh/?lang=pt

Costa, A. S.C. (2019). Construção de ilha de racionalidade baseada na temática formigas: uma experiência para professores de ciências em formação inicial. Dissertação. Universidade Tecnológica Federal do Paraná, Ponta Grossa, Brasil. https://repositorio.utfpr.edu.br/jspui/handle/1/4133

Fagundes, S. M. K., Piccini, I. P., Lamarque, T., \& Terrazzan, E. A. (2009). Produções em educação em ciências sob a perspectiva CTS/CTSA. In Anais do VII ENPEC, Florianópolis/SC/BR. http://abrapecnet.org.br/atas_enpec/vienpec/search0.html

Ferreira, M. V., Muenchen, C., \& Auler, D. (2019). Desafios e potencialidades em intervenções curriculares na perspectiva da abordagem temática. Ensaio Pesquisa em Educação em Ciências, 21. DOI: 10.1590/1983-21172019210108

Fourez, G. (1994). Alfabetización científica y tecnológica: acerca de las finalidades de la enseñanza de las ciencias. Ediciones Colihue SRL.

Fourez, G. (2003). Crise no ensino de ciências? Investigações em ensino de ciências, 8(2), 109-123. https://www.if.ufrgs.br/cref/ojs/index. php/ ienci/article/view/542/337

Freire, P. (1980). Educação como prática da liberdade. Editora Paz e Terra.

Freire, P. (1987). Pedagogia do oprimido. Paz e Terra.

Freitas, W. P. S., \& Queirós, W. P. (2019). O cenário das pesquisas sobre Formação de professores de ciências na perspectiva progressista. Investigações em Ensino de Ciências, 24(1), 154-178. DOI: 10.22600/1518-8795.ienci2019v24n1p154.

Freitas, W. P. S., \& Queirós, W. P. (2020a). A politização docente para o enfrentamento de uma situação-limite por meio de intervenções didáticas pautadas na perspectiva Giroux-CTS. Investigações em Ensino de Ciências, 25(2), 292-312. DOI: 10.22600/1518-8795.ienci2020v25n2p293.

Freitas, W. P. S., \& Queirós, W. P. (2020b). A abordagem CTS e a teoria crítica de Henry Giroux: caminhos para uma educação em ciências críticotransformadora. Revista Brasileira de Ensino de Ciências e Tecnologia, 13(3), 126-149. DOI: 10.3895/rbect.v13n3.10098.

Giroux, H. (1990). Literacy and the pedagogy of politics empowerment. In: Freire, P. \& Macedo, D. Literacy: Reading the word and the world. Routledge, 127.

Klein, S. G., Pereira, D. N., \& Muenchen, C. (2021). Avaliação da aprendizagem na abordagem temática: um olhar para os três momentos pedagógicos. Investigações em Ensino de Ciências, 26(1), 375-387. DOI: 10.22600/1518-8795.ienci2021v26n1p375.

Lisboa, E. A. (2017). Inserção da interdisciplinaridade na formação de licenciandos em física. Tese de Doutorado. Universidade Federal da Bahia, Salvador, Brasil. https://repositorio.ufba.br/ri/handle/ri/25771

Maingain, A., Dufour, B \& Fourez, G. (2008). Abordagens didáticas da interdisciplinaridade. Tradução de Joana Chaves. De Boerck \& Larcier. 
Research, Society and Development, v. 10, n. 7, e56510716888, 2021

(CC BY 4.0) | ISSN 2525-3409 | DOI: http://dx.doi.org/10.33448/rsd-v10i7.16888

Moraes, R., \& Galiazzi, M. C. (2013). Análise textual discursiva. Editora Unijuí.

Nicoletti, E. R. (2017). A interdisciplinaridade em diferentes contextos educacionais: contribuições para o ensino de biologia. Tese de Doutorado. Universidade Federal de Santa Maria, Santa Maria, Brasil. https://repositorio.ufsm.br/handle/1/13393

Oliveira, A. C. D. (2019). Alfabetização científica e tecnológica na formação inicial de professores de química. Dissertação. Universidade Federal de São Carlos, Araras, Brasil. https://repositorio.ufscar.br/handle/ufscar/11335

Ruas, P. A. A. R. (2017). Interdisciplinaridade, problematização e contextualização: a perspectiva de um grupo de professores em um curso de formação. Tese de Doutorado. Universidade de São Paulo, São Paulo, Brasil. https://www.teses.usp.br/teses/disponiveis/48/48134/tde-1005 2017-144001/pt-br.php

Santos, W. L. P., \& Mortimer, E. F. (2002). Uma análise de pressupostos teóricos da abordagem CTS (Ciência-Tecnologia-Sociedade) no contexto da educação brasileira. Ensaio Pesquisa em educação em ciências, 2(2), 1-23. https://www.scielo.br/j/epec/a/QtH9SrxpZwXMwbpfpp5jqRL/?lang=pt

Strefezza, T. F. (2020). As ilhas interdisciplinares de racionalidade na formação continuada de assessores pedagógicos: uma proposta interdisciplinar para o ensino de temas socioambientais. Dissertação. Universidade Estadual Paulista (UNESP), Bauru, Brasil. https://repositorio.unesp.br/handle/ 11449/192375 